\title{
Realitas Sosial Budaya Perilaku Hidup Bersih dan Sehat (Studi Kaum Perempuan Desa Bhuana Jaya Kecamatan Tenggarong Seberang Kabupaten Kutai Kartanegara)
}

\author{
Muhammad Habibi \\ Dosen Ilmu Administrasi Negara FISIP Universitas Widya Gama Mahakam Samarinda \\ e-mail: habibi.mayangmaurai@gmail.com
}

\begin{abstract}
Abstrak
Penelitian ini membahas Realitas Sosial Budaya Perilaku Hidup Bersih dan Sehat yang dipraktikkan oleh Kaum Perempuan Desa Bhuana Jaya. Penelitian ini menggunakan pendekatan kualitatif deskriptif.

Hasil penelitian menunjukkan, pertama, Kaum perempuan Desa Bhuana Jaya dalam mempraktekkan pengetahuan PHBS rumah tangga yang diperoleh dan dimiliki untuk kesejahteraan keluarga telah menunjukkan eksistensi sosial dari segi peran dan kedudukan sosial yang tinggi bagi keluarga dan masyarakat setempat.Kedua, Kaum perempuan Desa Bhuana Jaya telah memiliki jejaring akses untuk memperoleh informasi kesehatan terutama yang berhubungan dengan kendala penerapan PHBS didalam rumah tangga.
\end{abstract}

Kata kunci:Perempuan, Budaya, Kesehatan, dan PHBS.

\begin{abstract}
This study discusses the Social and Cultural Reality of Clean and Healthy Behavior Behavior practiced by Women of Bhuana Jaya Village. This research uses descriptive qualitative approach.

The results show, firstly, Bhuana Jaya Village women in practicing PHBS knowledge of households acquired and owned for family welfare have shown social existence in terms of role and high social standing for families and local communities.Secondly, women of Desa Bhuana Jaya have access network to get health information especially related with obstacle of PHBS implementation in household.
\end{abstract}

Keywords: Women, Culture, Health, and PHBS.

\section{Sosial Budaya Perilaku Hidup Bersih dan Sehat}

Kesehatan merupakan bagian yang penting untuk dimiliki oleh setiap individu agar dapat melakukan aktifitas. Kesehatan dapat mempengaruhi kinerja seseorang dalam beraktifitas sehingga memberikan hasil yang maksimal. Dengan adanya kesehatan, sumber daya manusia akan berkualitas secara fisik, mental, dan sosial serta mempunyai produktivitas yang optimal. Kesadaran akan pentingnya kesehatan perlu ditanamkan sejak usia sedini mungkin yang dimulai dari rumah dan keluarga terdekat.

Perilaku Hidup Bersih dan Sehat atau biasa populer dengan istilah PHBS menjadi sebuah keharusan bagi seluruh masyarakat Indonesia guna melahirkan kehidupan yang bahagia (happines). Konsep PHBS menjadi sangat mudah ketika telah menjadi bagian budaya seseorang, keluarga, atau masyarakat. Namun menjadi sulit diterapkan ketika budaya hidup bersih dan sehat tidak menjadi bagian budaya bagi seseorang, keluarga, atau masyarakat tertentu.

Berdasarkan beberapa kajian yang sudah ada oleh sejumlah peneliti dikatakan bahwa terkadang memerlukan waktu yang lama bahkan lintas generasi untuk merubah sosial budaya masyarakat -- 
termasuk dalam aplikasi pencapaian PHBS--, ketika karakter berhadapan dengan perkembangan peradaban dan pengetahuan khususnya bidang PHBS.

Pada kenyataan lain dalam kehidupan sehari-hari, seringkali begitu sering menemui perseorangan atau masyarakat yang dengan mudah dan entengnya membuang sampah sembarangan, ada yang kebawah kolong (bagi rumah panggung), samping dan pekarangan depan rumah, ada yang membuang sampah dari dalam mobil dan perahu atau kapal. Contoh lain seperti penggunaan air sungai yang kotor untuk melakukan aktifitas keseharian bahkan untuk mengolah bahan makanan untuk dijual kepada pelanggan. Intinya adalah banyak sekali perilaku yang menggambarkan ketidaksesuaian dengan konsep hidup bersih dan sehat.

Pada penelitian ini, peneliti berkeinginan untuk melaksanakan penelitian mengenai realitas sosial budaya PHBS yang dilakukan pada Perspektif Kaum Perempuan di Desa Bhuana Jaya Kecamatan Tenggarong Seberang Kabupaten Kutai Kartanegara. Di lokasi ini, pada tahun 2012 dan 2013 menjadi lokus kegiatan Praktek Belajar Lapangan bagi mahasiswa Fakultas Kesehatan Masyarakat Universitas Widya Gama Mahakam (UWGM) Samarinda. Sehingga layak untuk diketahui mengenai kesadaran masyarakat tentang pentingnya penerapan konsep PHBS pasca kegiatan penyuluhan dan praktik PHBS beberapa tahun yang lalu, terutama dari sudut pandang aktifitas sosial budaya.

\subsection{Masalah penelitian}

Permasalahan yang diangkat dalam penelitian ini adalah bagaimana cara para kaum perempuan dalam membudayakan PHBS dilingkungan keluarga? Dan solusi ketika pembudayaan tersebut terhambat?

\subsection{Tujuan penelitian}

Adapun yang menjadi tujuan dalam penelitian ini berdasarkan bahasan penelitian dalam latar belakang dan masalah penelitian di atas, sebagai upaya untuk mengetahui, memahami dan menggambarkan tentang cara para kaum perempuan dalam membudayakan PHBS dilingkungan keluarga dan solusi ketika upaya membudayakan PHBS dilingkungan keluarga terhambat.

\section{Budaya Perilaku Hidup Bersih dan Sehat}

Seorang bijak mengatakan "biasakan yang benar, bukan membenarkan yang biasa". Hal tersebut menunjukkan bahwa untuk membiasakan (baca: membudayakan) hal yang baik dan benar tidaklah mudah, karena sebagian masyarakat terpolarisasi membenarkan yang biasa (baca: budaya), atau dalam bahasa para motivator adalah berada dalam comfort zone.

Individu yang selalu merasa nyaman dalam wilayahnya akan mengalami "kejut sosial" ketika zaman berubah dengan cepat dan "mengusik" masa kejayaan yang telah lama dinikmati.

\subsection{Realitas}

Realitas atau dikenal sebagai sebuha kenyataan adalah "sesuatu yang bersifat materi dan objektif, yang mana hanya dapat dikenali dan dipahami lewat mekanisme intuisi dan indera, yang membawa pada sebuah pandangan materialism" (Piliang, 2010: 5).

Sedangkan menurut Goncing (2016:6) "memahami sebuah realitas, memang memerlukan sebuah penalaran danpenginderaan yang sangat kompleks. Sebab jika tidak seperti itu, maka pembacaan secarautuh terhadapnya terkadang tidak tepat sasaran yang dituju dan dengan sendirinya akanmenimbulkan sebuah pandangan yang tidak realistis".

Sedangkan dalam lingkup sosial budaya, Hidayatullah (2015:1) mendefiniskan realitas sebagai"kenyataan-kenyataan sosial budaya di sekitar lingkungan masyarakat tertentu. Kenyataan sosial budaya ini terjadi karena adanya pola-pola hubungan yang terjadi dalam masyarakat. Pola-pola hubungan tersebut dapat mencapai kestabilan tetapi dapat juga menimbulkan konflik".

Sehingga dapat dipahami bahwa realitas merupakan kenyataan sosial yang ada disekitar kitayang dikenali dan dipahami lewat mekanisme intuisi dan indera manusiawi. 


\subsection{Budaya dan Kebudayaan}

Mengacu pada konteks bahasa Indonesia, "kebudayaan berasal dari bahasa Sansakerta "buddhaya", yaitu bentuk jamak dari buddhi yang berarti budi atau akal" (Prasetya, dkk, 2011, 28). Sedangkan menurut Rafiek (2012) "budaya diartikan sebagai "hasil budi daya cipta manusia" sehingga dapat diartikan sebagai "keseluruhan gagasan, karya dan akal budi manusia yang diciptakannya dengan sengaja dan terus dikembangkan demi kepentingan, kebutuhan, kesejahteraan, kedamaian, kemakmuran, dan kepuasan hidupnya" (hlm.7).

E.B. Taylor dalam Setiadi dkk (2006) menyatakan bahwa "budaya adalah suatu keseluruhan kompleks yang meliputi pengetahuan, kepercayaan, kesenian, moral, keilmuan, norma, adat istiadat, dan kemampuan yang lain serta kebiasaan yang didapat oleh manusia sebagai anggota masyarakat" (hlm.27)

Menurut Koentjaraningrat dalam Muhammad (2011) bahwa kebudayaan itu paling sedikit memiliki 3 (tiga) wujud, yaitu:

a. Keseluruhan ide, gagasan, nilai, norma, peraturan, dan sebagainya yang berfungsi mengatur, mengendalikan, dan memberi arah pada kelakuan dan perbuatan manusia dalam masyarakat, yang disebut "adat tata kelakuan".

b. Keseluruhan aktifitas kelakuan berpola dari manusia dalam masyarakat, yang disebut "sistem sosial". Sistem sosial terdiri dari rangkaian aktifitas manusia dalam masyarakat yang selalu mengikuti pola-pola tertentu berdasarkan adat tata kelakuan, misalnya gotong royong dan kerjasama.

c. Benda-benda hasil karya manusia yang disebut "kebudayaan fisik", misalnya pabrik baja, Candi Borobudur, pesawat udara, 3omogeny, atau kain batik (hlm.75-76).

Dengan demikian secara keseluruhan budaya dan kebudayaan adalah menyangkut keseluruhan aspek kehidupan manusia baik fisik maupun non fisik sebagai hasil dari akal budi manusia yang bersifat komplek dan dilakukan secara terus menerus.

\subsection{Perilaku Hidup Bersih dan Sehat (PHBS)}

Sebelum membahas mengenai PHBS, ada baiknya dipahami terlebih dahulu konsep perilaku dari sisi sosiologi dan dari sisi kesehatan.

\subsubsection{Perilaku manusia dalam kesehatan}

Perilaku manusia pada hakikatnya adalah "suatu aktifitas dari manusia itu sendiri...yang mencakup berjalan, berbicara, bereaksi, berpakaian, dan lain sebagainya" (Notoatmodjo, 2011: 135).

Sedangkan Rokhman (2011:1) memberi definisi perilaku manusia sebagai "sekumpulan perilaku yang dimiliki oleh manusia dan dipengaruhi oleh adat, sikap, emosi, nilai, etika , kekuasaan, persuasi, dan/atau genetika".

Mengacu pada kedua pendapat diatas, maka perilaku manusia dapat dipahami sebagai suatu aktifitas manusia dalam keseharian yang dipengaruhi oleh lingkungan dan biologis.

Jika ditinjau dari sisi perilaku kesehatan, maka dapat didefinisikan sebagai "suatu respon seseorang (organisme) terhadap stimulus yang berkaitan dengan sakit dan penyakit, sistem pelayanan kesehatan, makanan serta lingkungan" (Notoatmodjo, 2011: 139). Sedangkan menurut pandangan Becker (1979) perilaku kesehatan "yaitu hal-hal yang berkaitan dengan tindakan atau kegiatan seseorang dalam memelihara dan meningkatkan kesehatannya. Termasuk juga tindakan-tindakan untuk mencegah penyakit, kebersihan perorangan, memilih makanan, sanitasi, dan sebagainya (Notoatmodjo, 2011: 143). Satu diantara perilaku kesehatan dari pelayanan kesehatan adalah program PHBS.

\subsubsection{PHBS}


Menurut Wiguna (2015:1) "PHBS merupakan singkatan dari Perilaku Hidup Bersih dan Sehat yaitu sekumpulan perilaku yang dipraktekkan atas dasar kesadaran sebagai upaya agar dirinya sehat dan aktif membantu kesehatan masyarakat di sekitarnya".

Perilaku Hidup Bersih dan Sehat (PHBS) adalah sekumpulan perilaku yang dipraktekkan atas dasar kesadaran sebagai hasil pembelajaran, yang menjadikan seseorang keluarga, kelompok atau masyarakat mampu menolong dirinya sendiri (mandiri) di bidang kesehatan dan berperan aktif dalam mewujudkan kesehatan masyarakat(Pedoman, 2011:7).

Oleh karena itu, terdapat banyak cara dan metode untuk membudayakan PHBS dikalangan masyarakat secara umum. Bahkan menurut Pedoman dari Kementerian Kesehatan RI (2011:7-8) dijelaskan bahwa PHBS mencakup 4omogen-ratus bahkan mungkin beribu-ribu perilaku yang harus dipraktekkan dalam rangka mencapai derajat kesehatan masyarakat yang setinggi-tingginya.

Berikut diuraikan beberapa contoh penerapan PHBS dari berbagai bidang, yakni:

a. bidang pencegahan dan penanggulangan penyakit serta penyehatan lingkungan harus dipraktekkan perilaku mencuci tangan dengan sabun, pengelolaan air minum dan makanan yang memenuhi syarat, menggunakan air bersih, menyediakan jamban sehat, pengelolaan limbah cair yang memenuhi syarat, memberantas jentik nyamuk, tidak merokok di dalam ruangan dan lain-lain.

b. bidang kesehatan ibu dan anak serta keluarga berencana harus dipraktekkan perilaku meminta pertolongan persalinan oleh tenaga kesehatan, menimbang balita setiap bulan, mengimunisasi lengkap bayi, menjadi akseptor keluarga berencana dan lain-lain.

c. bidang gizi dan farmasi harus dipraktekkan perilaku makan dengan gizi seimbang, minum Tablet Tambah Darah selama hamil, memberi bayi air susu ibu (ASI) eksklusif, mengkonsumsi Garam Beryodium dan lain- lain.

d. bidang pemeliharaan kesehatan harus dipraktekkan perilaku ikut serta dalam jaminan pemeliharaan kesehatan, aktif mengurus dan atau memanfaatkan upaya kesehatan bersumberdaya masyarakat (UKBM), memanfaatkan Puskesmas dan fasilitas pelayanan kesehatan lain dan lain-lain (Pedoman, 2011: 8).

Adapun penerapan PHBS pada lingkup rumah tangga menurut Pedoman dari Kementerian Kesehatan RI (2011:10) mencakup:

1) persalinan ditolong oleh tenaga kesehatan,

2) memberi bayi ASI eksklusif,

3) menimbang balita setiap bulan,

4) menggunakan air bersih,

5) mencuci tangan dengan air bersih dan sabun,

6) pengelolaan air minum dan makan di rumah tangga,

7) menggunakan jamban sehat (Stop Buang Air Besar Sembarangan/Stop BABS),

8) pengelolaan limbah cair di rumah tangga,

9) membuang sampah di tempat sampah,

10) memberantas jentik nyamuk,

11) makan buah dan sayur setiap hari,

12) melakukan aktifitas fisik setiap hari,

13) tidak merokok di dalam rumah dan lain-lain.

Dengan demikian, yang menjadi fokus aplikasi PHBS pada ranah domestik keluarga mencakup 13 poin diatas. Sehingga penilaian perilaku kesehatan pada ranah rumah tangga dapat diketahui seberapa sukses sebuah keluarga dapat berperilaku kesehatan sesuai dengan standar PBHS dari Kementerian Kesehatan Republik Indonesia.

2.4. Aktualisasi Kaum Perempuan dalam eksistensi sosial

Bhasin (2000:1) dalam Fadilawati (2011:1) menunjukkan bahwa "peran dan kedudukan perempuan di masyarakat dahulu masih berkisar didalam rumah tangga dan berkutat dengan 3M yaitu masak (memasak), macak (bersolek), dan maranak (melahirkan anak)". Pandangan lain menyatakan bahwa "perempuan lebih sering 
dikonotasikan bahwa perempuan hanya memiliki tiga tempat yaitu dapur, sumur, dan kasur" (Azizah, 2015:1).

Berdasarkan pandangan tersebut dapat dipahami bahwa terjadi perbandingan yang begitu besar antara laki-laki dan kaum perempuan. Melalui patron 3M atau dapur, sumur, dan kasur. Dimana kaum perempuan hampir pasti tidak memiliki akses keranah publik, sebuah wilayah yang hanya dikuasai oleh kaum laki-laki.

Lebih jauh Azizah (2015:1) mengatakan bahwa "yang menjadi penghambat aktualisasi dan partisipasi bagi perempuan. Secara konseptual aktualisasi memiliki makna dorongan untuk menjadi seseorang yang berarti dan mampu berbuat sesuatu seperti pencapaian potensi. Bentuk aktualisasi 5omo berupa membangun hubungan interpersonal dengan orang maupun kelompok. Pada hakikatnya perempuan juga memiliki andil dalam masyarakat, dibidang ekonomi, sosial, budaya, hingga politik".

Fadilawati (2011:1) menegaskan bahwa "dulu perempuan memiliki peran dan tanggung jawab terhadap pemeliharaan keutuhan keluarga, sedangkan laki-laki memiliki peran dan tanggung jawab dalam hal pemenuhan ekonomi keluarga. Namun, dengan adanya pergerakan kaum perempuan mendorong terjadinya perubahan yang membuat perempuan kini mampu mengekspresikan diri tidak hanya di ranah 5omogeny tetapi juga diruang public".

Dengan demikian, peran perempuan saat ini tidak lagi pada ranah domestic saja, keberadaan perempuan di ruang 5omoge mulai diakui. Terbukti banyak tokoh perempuan hebat seperti ratu Elizabeth, ratu Rania, Kartini, Aung San Suu Kyi, Hillary Clinton, mantan presiden ibu Megawati, dan lainnya.

Pada tahun 2000 pemerintah Indonesia melalui menerbitkan Instruksi Presiden no. 9 tahun 2000 tentang pengarus utamaan gender dalam pembangunan mulai memperhatikan peran perempuan dalam pembangunan. Dan hal tersebut menjadikan kaum perempuan sebagai salah satu aktor pembangunan terutama dalam konsep kesejahteraan sosial, termasuk aktor penggerak PHBS pada tatanan rumah tangga, sebagai kapital sosial menyiapkan generasi yang unggul untuk membangunan Indonesia kedepan.

\section{Metode Penelitian}

3.1. Jenis dan pendekatan Penelitian

Berdasarkan pertanyaan dan tujuan penelitian, maka jenis penelitian ini adalah penelitian kualitatif dengan pendekatan deskriptif atau bersifat "menggambarkan"realitas sosial budaya Perilaku Hidup Bersih dan Sehat yang dipraktikkan oleh Kaum Perempuan Desa Bhuana Jaya.

\subsection{Teknik Pengumpulan Data}

Adapun teknik pengumpulan data pada penelitian ini dilakukan melalui studi kepustakaan, wawancara mendalam, dan observasi.

\subsection{Teknik Analisis Data}

Analisis menggunakan model analisis interaktif teori Miles dan Huberman (1994), yakni reduksi data, tampilan data, kesimpulan: gambaran dan verifikasi.

\section{Desa Bhuana Jaya dan Eksistensi Kaum Perempuan}

4.1. Sejarah dan Kondisi Desa Bhuana Jaya

Desa Bhuana Jaya yang sering disebut Separi III merupakan desa bentukan dari Departemen Trasmigrasi era tahun delapan puluhan yang saat itu merupakan UPT.SP2 Separi. Kata Separi sendiri merupakan desa adat yang sudah ada sebelum Bhuana Jaya terbentuk.

Sebagai desa bentukan, Bhuana Jaya tentunya memiliki latar belakang 5omoge budaya yang beragam dan mayoritas merupakan etnis jawa (70\%), Sunda ( $20 \%$ ) dan $10 \%$ merupakan penduduk 5omog ( Kutai, Dayak dan Banjar). Dengan keanekaragaman etnis 
tersebut menjadikan Desa yang kaya akan budaya yang selalu menjunjung tinggi nilai- nilai kebhinekaan yang bersatu untuk mencapai tujuan dan kejayaan bersama.

Gambar 3.1. Gerbang Desa Bhuana Jaya

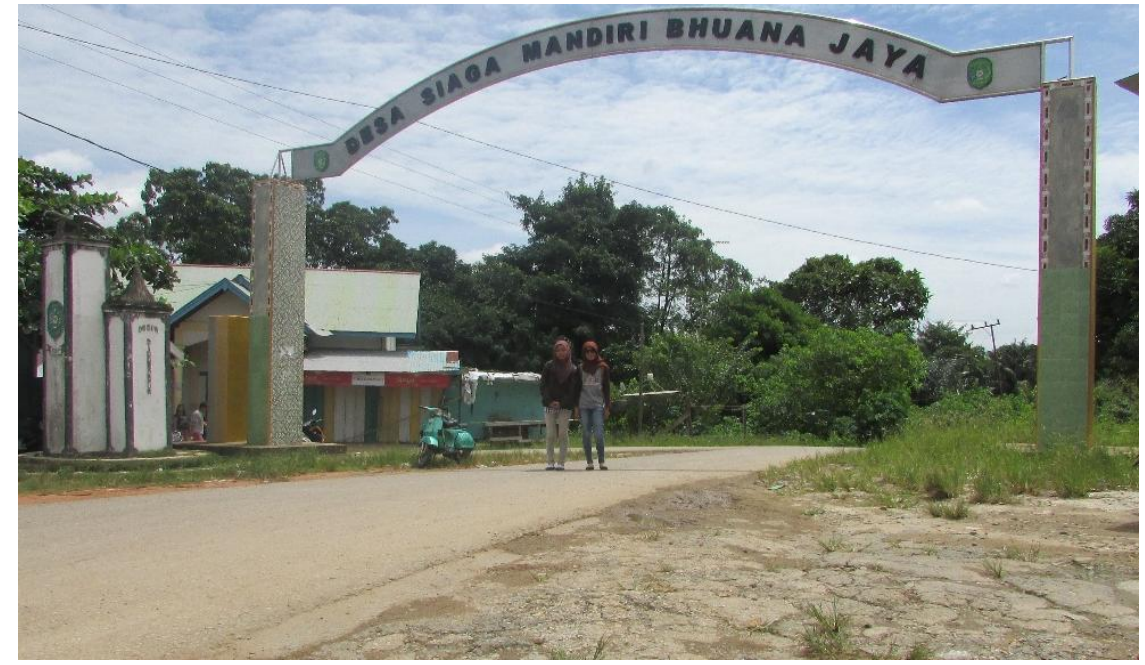

Sumber: Dokumentasi enumerator

\section{Gambar 3.2. Kantor Desa Bhuana Jaya}

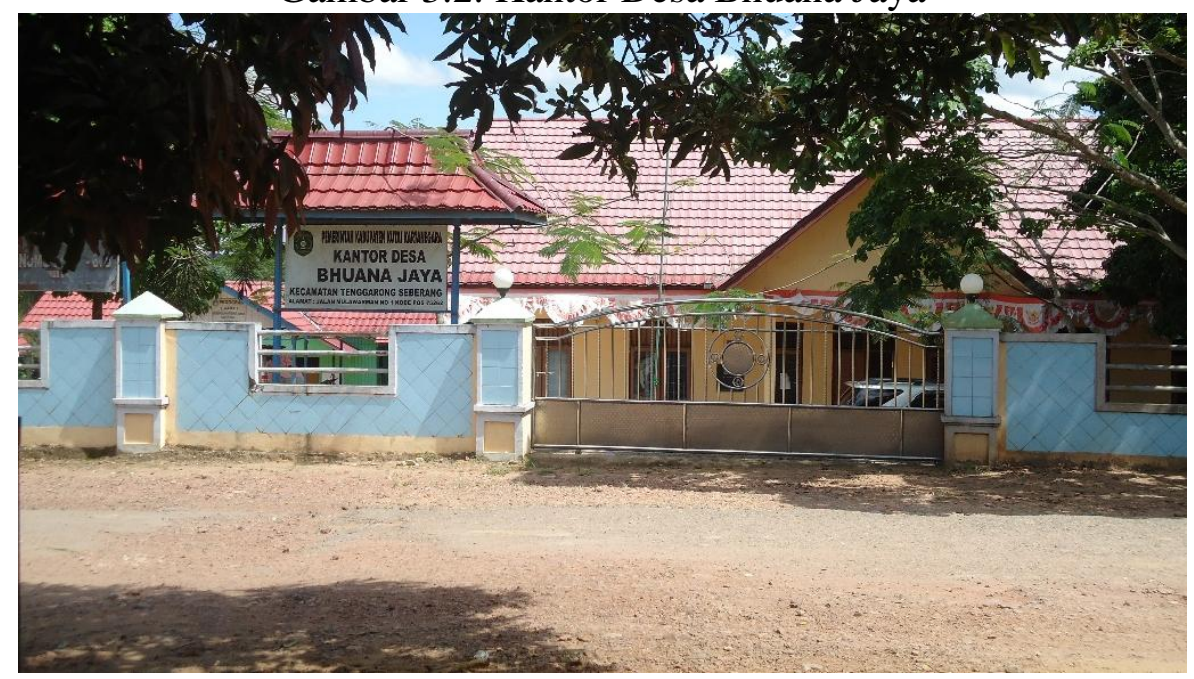

Sumber: Dokumentasi peneliti

Jarak tempuh sekitar $45 \mathrm{Km}$ dari Pusat pemerintahan Kabupaten dan $18 \mathrm{Km}$ dari Desa Manunggal Jaya sebagai Ibu Kota Kecamatan. Terdiri dari empat (4) Dusun yakni Dusun Sidomakmur, Dusun Mekarsari, Dusun Bina Mulya, dan Dusun Bina Mas. Desa ini memiliki 23 RT (Rukun Tetangga). 
Gambar 3.3. Peta Desa Bhuana Jaya

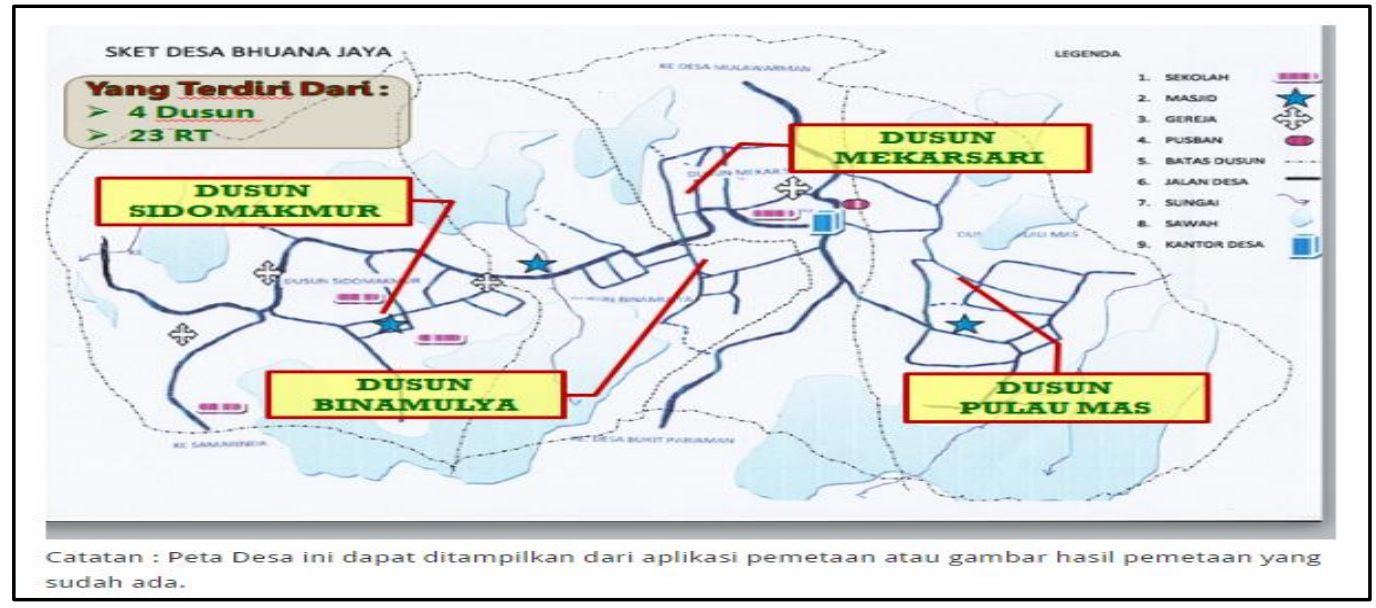

Sumber: http://bhuanajaya.desa.id/profil/

\subsection{Sosial Budaya}

Desa ini sebagian besar penduduknya bermata pencaharian sebagai petani ladang dan petani sawah, yang didukung oleh potensi perikanan dan peternakan. Selain itu di wilayah desa ini juga menjadi lokasi eksplorasi pertambangan Batu Bara PT. Khotai Makmur.

Kondisi umum sosial budaya, masih bercirikan kondisi perdesaan dengan segala aktifitas yang mendirikan masyarakat desa, diantaranya adalah jenis pekerjaan yang cenderung homogen (sama), sangat menggantungkan pekerjaan kepada keluarga lain, dan sebagaimana konsepFerdinand Tonnies bahwa masyarakat desa bersifat gemainschaft (peguyuban) dimana kelompok masyarakat yang anggotanya sangat terikat secara emosional satu dengan lainnya.

\subsection{Eksistensi Kaum Perempuan}

Berdasarkan kegiatan peneliti yang dilakukan beberapa kali mengunjungi Desa Bhuana Jaya bahwa secara umum terutama kaum perempuan memiliki 2 (dua) aktifitas utama yang menyatukan mereka yakni aktifitas keagamaan dan aktifitas sosial budaya.

Untuk aktifitas sosial budaya, para perempuan di Desa Bhuana Jaya disatukan oleh kegiatan pewarisan budaya leluhur terutama dari Jawa, yakni melalui kegiatan Sanggar Budaya Kuda Lumping Campur Sari Turonggo Sri Margo Mulyo sebagaimana yang telah tim peneliti sampaikan pada penelitian sebelumnya dengan tema "Peran Tokoh Masyarakat Sebagai Aktor Penerus Warisan Budaya Di Tanah Perantauan (Studi: Sanggar Budaya Kuda Lumping Campur Sari Turonggo Sri Margo Mulyo Desa Bhuana Jaya, Kecamatan Tenggarong Seberang Kabupaten Kutai Kartanegara)" pada tahun 2015.

Sedangkan untuk aktifitas keagamaan, para perempuan di Desa Bhuana Jaya disatukan oleh kegiatan kelompok pengajian Ibu-ibu, dan kegiatan maulid. Untuk kegiatan pengajian, para perempuan Desa juga menyelipkan kegiatan arisan dan kegiatan sosial lain, termasuk jika ada penyuluhan dari Tim Penggerak PKK kecamatan, penyuluh kesehatan, dan kegiatan serupa yang lain. 
Tim peneliti pun pada 2 (dua) kesempatan bertemu dengan para perempuan desa melalui kegiatan ini, terutama untuk menggali informasi yang berkenaan dengan Realitas Sosial Budaya Perilaku Hidup Bersih dan Sehat di Desa Bhuana Jaya tahun 2016.

\subsection{Kaum Perempuan Desa Dalam Mewujudkan PHBS Rumah Tangga}

\subsubsection{Metode para kaum perempuan dalam membudayakan PHBS}

Berdasarkan informasi berdasarkan wawancara yang peneliti peroleh dari para inforwoman, maka dapat dipahami bahwa para kaum perempuan Desa Bhuana Jaya telah berusaha maksimal untuk membudayakan PHBS dilingkungan rumah tangga mereka dengan segala keterbatasan kondisi dan akses. Upaya tersebut sebagaimana pengetahuan yang mereka peroleh dari para penyuluh kesehatan baik dari FKM UWGM Samarinda saat melaksanakan kegiatan PBL, petugas kesehatan dari puskesmas maupun Dinas Kesehatan dan Dokter serta petugas dari pihak aparatur desa.

Kondisi tersebut sebagaimana yang dikemukakan oleh Wiguna (2015:1) dan pedoman PHBS (2011:7) pada Bab 2, bahwa perilaku yang dipraktekkan berdasarkan kesadaran agar mampu menolong diri, keluarga, dan kelompok masyarakatnya. Meskipun secara menyeluruh belum dapat memenuhi 13 (tiga belas) cakupan PHBS rumah tangga dari Kementerian Kesehatan Republik Indonesia (2011:10) pada Bab 2. Namun, semangat yang tinggi untuk hidup sehat dan bersih sudah dapat menjadi modal dasar para kaum perempuan di Desa Bhuana Jaya.

\subsubsection{Kendala dan Solusi pembudayaan PHBS dilingkungan keluarga}

Mengacu pada kutipan wawancara dengan para inforwomen menunjukkan bahwa para kaum perempuan Desa Bhuana Jaya telah memiliki jejaring akses untuk memperoleh informasi kesehatan terutama yang berhubungan dengan penerapan PHBS didalam rumah tangga mereka baik tingkat Rukun Tetangga, Dusun, Desa bahkan hingga Dinas Kesehatan Kabupaten Kutai Kartanegara.

Sehingga ketika mereka menemukan keterbatasan pemahaman unsur PHBS, dalam waktu yang relatif tidak lama kaum perempuan dapat memperoleh pengkinian informasi atau solusi dari permasalahan yang dihadapi.

\subsection{Pembahasan}

Secara menyeluruh dari poin diatas menunjukkan bahwa eksistensi kaum perempuan Desa Bhuana Jaya dalam mempraktekkan pengetahuan PHBS rumah tangga yang diperoleh dan dimiliki untuk kesejahteraan keluarga telah menunjukkan eksistensi sosial dari segi peran dan kedudukan sosial yang tinggi bagi keluarga dan masyarakat setempat.

Realitas tersebut telah mengangkat harkat dan martabat kaum perempuan dari zona 3M yaitu masak (memasak), macak (bersolek), dan maranak (melahirkan anak) sebagaimana teori yang dikemukakan oleh Bhasin (2000:1) dalam Fadilawati (2011:1) poin 2.4 pada Bab 2 sebelumnya.

Dengan demikian realitas perempuan saat ini tidak lagi hanya berada pada ranah domestik, tetapi juga ranah publik yang membawa kekuatan kedalam ranah domestik terutama dalam perwujudan kesejahteraan dari segi kesehatan, khususnya kesehatan keluarga.

Penguatan jejaring kaum perempuan Desa Bhuana Jaya kepada stakeholders setempat terutama bidang kesehatan melalui puskesmas dan aparatur desa telah memudahkan mereka dalam pengayaan pengetahuan, sikap dan perilaku hidup sehat dan bersih.

Selain dari sesi kesehatan, peran kaum perempuan Desa Bhuana Jaya telah mencapai 3 (tiga) wujud kebudayaan sebagaimana yang diuraikan oleh Koentjaraningrat pada poin 2.2. Bab 2, yakni wujud ideal pola hidup sehat, sistem aktifitas hidup sehat, dan kebudayaan fisik dalam hidup sehatbaik dalam bentuk budaya, makanan, dan sistem praktek PHBS dalam skala rumah tangga.

\section{Simpulan}


5.1. Kaum perempuan Desa Bhuana Jaya dalam mempraktekkan pengetahuan PHBS rumah tangga yang diperoleh dan dimiliki untuk kesejahteraan keluarga telah menunjukkan eksistensi sosial dari segi peran dan kedudukan sosial yang tinggi bagi keluarga dan masyarakat setempat.

5.2. Kaum perempuan Desa Bhuana Jaya telah memiliki jejaring akses untuk memperoleh informasi kesehatan terutama yang berhubungan dengan kendala penerapan PHBS didalam rumah tangga.

\section{Daftar Referensi}

Buku:

Alston, Margaret.,\& Wendy Bowles. 2003. Research for social workers: and introduction to methods $\left(2^{\text {nd }}\right.$ ed. $)$. Canberra: Allen\&Unwin.

Denzim, Norman K., Yvonna S. Lincoln. 2009. Handbook of qualitative research (Dariatno dkk, Penerjemah). Yogyakarta: Pustaka Pelajar.

Irawan, Prasetya. 2006. Penelitian kualitaif \& kuantitatif untuk ilmu-ilmu sosial. Depok: Departemen Ilmu Administrasi FISIP UI.

Miles, Matthew B., \& A. Michael Huberman. 1994. Qualitative data analyses (second edition). London: SAGE Publications.

Moleong, Lexy J. 2010. Metodologi penelitian kualitatif (Ed. Revisi). Bandung: PT. Remaja Rosdakarya.

Muhammad, Abdulkadir. 2011. Ilmu Sosial dan Budaya Dasar. Bandung: PT. Citra Aditya Bakti.

Ndraha, Taliziduhu. 2010. Metodologi ilmu pemerintahan. Jakarta: Rineka Cipta.

Neuman, W. Lawrence. 2006. Social Research Methods: Qualitatative and Quantitative Approaches. (4 th ed). USA: Allyn and Bacon.

Notoatmodjo, Soekidjo. 2011. Kesehatan masyarakat: ilmu dan seni. Jakarta: PT. Rineka Cipta.

Ogden, Russel. (2008). "Informant". Ed. Given, Lisa M. The sage encyclopedia of qualitative research methods volumes 1 \& 2. UK: London, SAGE Publications, Inc. 430-431.

Prasetya, Joko Tri. 2011. Ilmu Budaya Dasar. Jakarta: Rineka Cipta.

Raco, J.R. (2010). Metode penelitian kualitatif: jenis, karakteristik dan keunggulannya. Jakarta: PT. Gramedia Widiasarana Indonesia.

Rafiek, M. 2012. Ilmu Sosial dan Budaya Dasar. Yagyakarta: Aswaja Pressindo.

Schensul, Jean J. (2008). "Methodology". Ed. Given, Lisa M. The sage encyclopedia of qualitative research methods volumes 1 \& 2. UK: London, SAGE Publications, Inc. 516-521.

Setiadi, Elly M., Kama A. Hakam, \& Ridwan Effendi. 2006. Ilmu Sosial dan Budaya Dasar (Ed.2). Jakarta: Kencana.

Strauss, Anselm L. (1987).Qualitative analysis for social scientists. UK:Cambridge University Press.

Sugiyono.(2005). Memahami Penelitian Kualitatif, Bandung: Alfabetha

Sugiyono. (2010). Metode penelitian kuantitatif, kualitatif dan R\&D. Bandung: Alfabeta

Topatimasang, Roem., Mansur Faqih, dan Toto Rahardjo.(2000). Mengubah Kebijakan Publik, Yogyakarta: Pustaka Pelajar

Piliang, Yasraf Amir, 2010, Post-Realitas:Realitas Kebudayaan Dalam Era Post-Metafisika,Jalasutra, Yogyakarta. 
Vanderstoep, Scott W., \& Dierdre D. Johnston. (2009). Research methods for everyday life: blending qualitative and quantitative approaches. CA: San Fransisco. John Wiley \& Sons, Inc.

Walliman, Nicholas. (2006). Social Research Methods. UK: London SAGE Publications

$\underline{\text { Jurnal: }}$

Krefting, Laura. (1991). Rigor in qualitative research: the assessment of trustworthiness. The American Journal of Occupational Therapy, 214-222. Vol. 45, No. 3.

\section{Penelitian:}

Fadilawati, Evi. (4815111569). 2011. Kesetaraan Gender: Peran Perempuan dalam Meningkatkan Kesejahteraan Ekonomi Keluarga. Universitas Negeri Jakarta: Fakultas Ilmu Sosial Pendidikan Sosiologi Reg. http://www.academia.edu/8383548/Kesetaraan_Gender_Peran_Perempuan_dalam_Meningkatk an_Kesejahteraan_Ekonomi_Keluarga

\section{Dokumen Lembaga:}

Instruksi Presiden Republik Indonesia Nomor 9 Tahun 2000 Tentang Pengarusutamaan Gender Dalam Pembangunan Nasional.

Kementerian Kesehatan RI. 2011. Pedoman pembinaan perilaku hidup bersih dan sehat (PHBS).

Pemerintah Kabupaten Kutai Kartanegara. 2016. Asal usul desa Bhuana Jaya. http://bhuanajaya.desa.id/profil//

Badan Pusat Statistik Kutai Kartanegara. 2015. Kutai Kartanegara dalam angka.

Website:

Azizah, Nur. 2015. Aktualisasi Dan Partisipasi Perempuan Dalam Usaha Kesejahteraan Melalui Program Pemberdayaan Kesejahteraan Keluarga (PKK)http://nurazizahaziz.web.unej.ac.id/2016/01/28/aktualisasi-dan-partisipasi-perempuandalam-usaha-kesejahteraan-melalui-program-pembinaan-kesejahteraan-keluarga-pkk/

Goncing, Muhammad Abdi. 2016. Bahasa, Pikiran, dan Realitas. Diunduh pada 19 Mei 2016. http://www.academia.edu/2025853/bahasa_pikiran_dan_realitas

Hidayatullah, Wahyu. 2015. Pengertian dankonsep realitas sosial budaya.Diunduh pada 19 Mei 2016.http://www.trendilmu.com/2015/06/pengertian-dan-konsep-realitas-sosial.html\#

Rohman, Fatkhur. 2011. Perilaku manusia \& nilai sosial. Di download 19 Mei 2016. http://ruhtaf12.blogspot.co.id/2011/12/perilaku-sosial-dan-perubahan-sosial.html

Sumirta, I Nengah. 2011. Peranan Perempuan Dalam Pelayanan Kesehatan Dasar (Primary Health Care). Di download 19 Mei 2016. http://ramakrisnahare.blogspot. co.id/2011/06/ perananperempuan-dalam-pelayanan.html

Wiguna, Candra. 2015.Perilaku hidup bersih dan sehat untuk anak sekolah. Di download 19 Mei 2016. http://duniaiptek.com/perilaku-hidup-bersih-dan-sehat-untuk-anak-sekolah/ 